\title{
Effect of Surface Sterilization Time on Leaf Explants for Aseptic Culture in Anthurium adraeanum (Hort.) cv. Fire
}

\author{
Rashmita Toppo $^{1} *$ and Sashikala Beura ${ }^{2}$ \\ ${ }^{1}$ Floriculture and Landscaping, College of Agriculture, OUAT \\ ${ }^{2}$ Floriculture and Landscaping, College of Agriculture and BTCC, OUAT \\ *Corresponding author
}

\section{A B S T R A C T}

Keywords

Anthurium, Sterilization, Survival, $\mathrm{HgCl}_{2}$

Article Info

Accepted:

17 June 2018

Available Online:

10 July 2018
Anthurium is an important ornamental plant grown around the globe and also in India. Seed and vegetative propagation of this plant are tedious and very slow process and not practical when carried out on a large scale. Therefore, biotechnological approach such as in-vitro cloning is found to be a novel method for production of pathogen free true-to-type plantlets at a faster rate. In this study, a competent surface sterilization procedure was standardized for aseptic in-vitro culture from leaf explants of Anthurium adraeanum (Hort.) $c v$. Fire under in vitro conditions. The leaf explants were treated with $0.1 \% \mathrm{HgCl}_{2}$ (2, 3, 4, 5, 6, 7 and $8 \mathrm{~min}$ ) and control (distilled water) were cultured on MS media. The leaf explants treated for 5 minutes resulted in minimum fungal $(0.00 \%)$ and bacterial $(0.00 \%)$ contamination with maximum survival percentage $(100 \%)$. The best surface sterilization time was taken into consideration for further sterilization explants and in-vitro culture in the MS Basal media supplemented with of BAP alone or in combination with NAA and 2,4-D along with control for production of pathogen free true-to-type plantlets in a faster rate.

\section{Introduction}

Anthurium is an important tropical ornamental plant grown for its colourful spathe and attractive foliage. Although, Anthurium is sold both as cut flower and potted plant, the trade in cut flower is much larger than the potted plant. The traded value of Anthurium exceeds its position ahead of Cymbidium among tropical orchids among the tropical flowers (CBIMI, 2016). They are very popular as cut flowers for their beauty, bold and long lasting qualities which are essential pre-requisites for any floral arrangement. The five major spathe colours are red, orange, pink, coral, and white. Usually bi-colours like red-green, orangegreen, pink green and white green are known as obake and they are extremely variable in size and shape.

Anthurium is conventionally propagated by seeds and, therefore, cultivation is hindered by problems due to the inherent heterozygosis as well as lengthy process of seed setting and 
maturity. Although, traditional techniques of vegetative propagation such as stem cuttings and suckers exist, despite of homogenous materials, it is tedious and very slow process and not practical when carried out on a large scale. Anthurium is also propagated through seed. However, the process is lengthy and the seeds derived plants show low seedling vigour, poor vegetative growth and some amount of variability. Now-a-days biotechnological approach such as in- vitro cloning is found to be a novel method for production of pathogen free true-to-type plantlets in a faster rate.

The major producers are Hawaii, Holland, Mauritius, Caribbean countries and Philippines. Besides the European and American markets, Asia is the most rapidly growing market for Anthuriums. Hence, there is good scope for export of Anthuriums to Japan, Hong Kong, Singapore, Taiwan and the Middle East countries (Prasad et al., 1998).

Anthurium is commercially cultivated in Kerala, Karnataka, Tamil Nadu, West Bengal, Sikkim, Maharastra and pockets of North Eastern parts of India under semi-shade condition. However, in Odisha its commercial cultivation has not yet been started but cut anthurium flowers are widely used in bouquets and flower arrangements and mainly they are procured from Tamil Nadu, Karnataka, West Bengal and Sikkim. Many suitable varieties of Anthurium can be grown commercially under protected structures in Odisha, but planting materials are quite costlier as well as transportation cost increases as procured from outside states. Hence, there is an urgent need for disease free healthy planting materials of suitable varieties, so that they can be recommended for commercial cultivation in Odisha under low cost technology i.e., poly shade-net structure. Therefore, the present investigation with the above background was being carried out for production of true-to- type plantlets through in-vitro cloning. But the most crucial and challenging step followed under in-vitro cloning is sterilization of explants for aseptic culture establishment. Sterilization is the method of making explants contamination free before establishment of culture. Contamination of explants depends on the several plant and environmental factors like, species, age, source of explants, growing condition and prevailing macro and micro climatic conditions. Losses due to contamination under in-vitro conditions vary between $3-15 \%$ on an average at each subculture in the majority of commercial and scientific plant tissue culture laboratories (Leifert et al., 1989), mainly caused by fungus, yeast and bacteria (Leifert et al., 1994). Taking all these into consideration, the objective of the present study was to establish a protocol for standardization of surface sterilization time for leaf explants of Anthurium andraeanum (Hort.) $c v$. Fire, to obtain pathogen free culture.

\section{Materials and Methods}

\section{Sterilization of glassware and tools}

All the glassware and culture tubes were dipped in the diluted (10x) chromic acid solution overnight and washed thoroughly with detergent solution followed by washing under running tap water. They were rinsed with distilled water several times and then dried in a hot air oven for 2 hours at $150^{\circ} \mathrm{C}$. Forceps, Petridish and Scalpel were thoroughly cleaned with iso-propanol, wrapped with paper and kept in a clean sterilized autoclave at $15 \mathrm{psi}$ and $121^{\circ} \mathrm{C}$ for 20 minutes. The working chamber of laminar air flow cabinet was wiped with iso-propanol. Filtered air (80-100 cft/min) to ensure that particles do not settle in working area was blown for 5 minutes. The sterilized tools were kept in the chamber and exposed to UV light for 30 minutes. 


\section{Media preparation and sterilization}

Analytical reagents of excel $\mathrm{R}$ grade of Titan Biotech Ltd., Ranbaxy Laboratory Ltd., Merck (India), Qualigen Fine Chemicals, and Himedia Laboratories Ltd. (India) were used in the present study. MS Medium (Murashige and Skoog, 1962) was used throughout the investigation. Auxins, Cytokinins, Myoinositol and Fe-EDTA used for media preparation were supplied by Sigma (USA) and Agar from Ranbaxy Laboratory Ltd.

Required quantities of macronutrients, micronutrients, vitamins and plant bioregulator's were taken from the stock solution and required quantity of sucrose dissolved in distilled water was added fresh to the medium.

The $\mathrm{pH}$ of the solution was adjusted to $5.6 \pm$ 0.1 using $0.1 \mathrm{~N} \mathrm{NaOH}$ or $0.1 \mathrm{~N} \mathrm{HCl}$ and volume was made up to $1 \mathrm{~L}$ with distilled water. After adding Agar $(0.6 \% \mathrm{w} / \mathrm{v})$ as gelling agent to the medium, it was then boiled and poured into the culture tube and plugged.

Culture tube containing culture medium was autoclaved at $121^{\circ} \mathrm{C}$ and 15 psi pressure for the 20 minutes. The autoclaved medium was then kept in laminar air flow chamber for cooling.

\section{Source of explants}

The investigation was carried out at Biotechnology-cum-Commercial Tissue Culture Centre, OUAT, Bhubaneswar, during the year 2013-15. Healthy and disease free $3^{\text {rd }}$ and $4^{\text {th }}$ light green coloured leaves of Anthurium adraeanum cv. Fire were collected from the mother plants maintained under shade net-house in the Biotechnology-cumCommercial Tissue Culture Centre, OUAT, Bhubaneswar for conducting in vitro in the laboratory.

\section{Surface sterilization of explants}

The leaves were collected using clean blades from the mother plants. They were washed under running tap water. The surface sterilisation procedure was undertaken in two phases, i.e. Phase-I: outside laminar air flow chamber and Phase - II: inside laminar air flow chamber.

\section{Phase-I}

Leaf explants obtained from the mother plants were cut into segments for easy handling and subjected to running tap water for 30 minutes followed by washing in $1 \%$ Tween 20 solution for 15 minutes. Then the explants were treated with $2 \%$ solution of Carbendazim 50\% WP for 20 minutes and rinsed 3-4 times with distilled water. These explants were then taken to the laminar air flow chamber for further sterilization.

\section{Phase-II}

The laminar air flow chamber was wiped with $70 \%$ iso-propanol. Inside the laminar flow the leaf explants were treated with $0.1 \% \mathrm{HgCl}_{2}$ with time of exposure for $\mathrm{T}_{2}-2 \mathrm{~min}, \mathrm{~T}_{3}-3$ min, $\mathrm{T}_{4}-4 \mathrm{~min}, \mathrm{~T}_{5}-5 \mathrm{~min}, \mathrm{~T}_{6}-6 \mathrm{~min}, \mathrm{~T}_{7}-7$ min and $\mathrm{T}_{8}-8$ mins; followed by rinsing 5-6 times with sterile water. Explants were then rinsed with $0.1 \% \mathrm{KCl}$ solution for $1 \mathrm{~min}$ for dissolving the residual mercury as it is toxic to both plant and animal and again rinsed 4-5 times with sterile water. For control $\left(\mathrm{T}_{1}\right)$ explants were only washed with distilled water 5-6 times.

\section{Inoculation}

These sterilized leaf explants were trimmed suitably to remove sterilizing agent affected parts/brown parts to obtain appropriate size of $1 \mathrm{~cm}^{2}$ and then inoculated on Murashige and Skoog (1962) medium supplemented with 
growth hormones BAP $(2.0 \mathrm{mg} / \mathrm{l})$ and 2, 4-D $(0.5 \mathrm{mg} / \mathrm{l})$ with $6 \%$ (w/v) agar, $30 \%(\mathrm{w} / \mathrm{v})$ sucrose. Observation for different parameters i.e., fungal, bacterial, death, aseptic and survival percentage of explants were recorded at 15, 30, 45 and 60 DAI (Days after inoculation). The treatment having the maximum survival percentage with minimum infection and death percentage were taken as the standard time for sterilizing explants for further in vitro propagation.

\section{Establishment of culture}

After inoculation, the culture were kept at $25 \pm 2{ }^{\circ} \mathrm{C}$ in an air conditioned room with 2 months dark period and $80 \%$ relatively humidity.

\section{Statistical analysis}

The experiment was performed in completely randomized design with three replications. The raw data obtained during the experimental observations were subjected to statistical analysis as per method by Gomez and Gomez, (1984). The significance and non- significance of the treatment effect were judged with the help of ' $F$ ' variance ratio test. Calculated ' $F$ ' value was compared with the table value of ' $F$ ' at 5\% level of significance. The data were transformed wherever required for Analysis of Variance (ANOVA).

\section{Results and Discussion}

After observing the inoculated explants for 60 days for contamination, it was found that increasing time of exposure to $\mathrm{HgCl}_{2}$ significantly reduced contamination but showed adverse effect on explants. Sterilization time response of leaf explants of Anthurium andraeanum cv. Fire in relation to the time of exposure is depicted in Table 1,2, 3 and 4 . The data revealed that among the different treatments for the tissue cultured leaf explants, maximum fungal contamination percentage $(48.28 \%)$ recorded with control ( $\mathrm{T}_{1}$-distilled water) and with 5 min exposure to $\mathrm{HgCl}_{2}$ minimum fungal contamination $(0.00 \%)$ was recorded followed by $6 \mathrm{~min}$ treatment with $0.63 \%$ fungal contamination at 15 DAI (Table 1). Bacterial contamination was recorded maximum with control $(26.80 \%)$ and minimum $(0.00 \%)$ was recorded with 5 $\min , 6 \mathrm{~min}, 7 \mathrm{~min}$ and $8 \mathrm{~min}$ exposure at15 DAI. In case of explants death, maximum (6.41\%) was recorded with 8 min exposure and minimum death of explants $(2.52 \%)$ was observed with $5 \mathrm{~min}$ exposure. Maximum percentage of aseptic culture $(100.00 \%)$ was recorded at $5 \mathrm{~min}$ followed by $6 \mathrm{~min}(99.37 \%)$ and the minimum were obtained in $\mathrm{T}_{1}(24.92$ $\%$ ). Maximum survival percentage of explants was obtained at $5 \mathrm{~min}(97.48 \%)$ and minimum with distilled water $(21.13 \%)$. The mean percentage of clean surviving explants showed that the effectiveness of the sterilization procedure was maximum (97.48\%) with $5 \mathrm{~min}$ as compared to other treatments. Further increase in exposure time to $\mathrm{HgCl}_{2}$ led to a significant decline in percentage survival of explants.

Observation recorded at 30 DAI (Table 2) showed that the explants treated for $5 \mathrm{~min}$ resulted with minimum fungal $(0.00 \%)$, bacterial $(0.00 \%)$ contamination with $100.00 \%$ aseptic culture and maximum survival percentage $(96.74 \%)$. Results obtained at 45 DAI and 60 DAI (Table 3 and 4) also showed the similar fashion with $0.00 \%$ fungal and bacterial contamination in both the cases treated for $5 \mathrm{~min}$. The explants that did not survive the whole process were seen maximum $(7.10 \%)$ with 8 min time exposure to $\mathrm{HgCl}_{2}$ at 60 DAI and maximum survival percentage of explants $(96.39 \%)$ was recorded with 5 min time exposure.

The surface sterility chosen for explants characteristically depends on the type of 
explants as well as plant species (Rezadost $e t$ al., 2013). Sterilization time exposure may vary for different plant parts depending on their morphological characters like softness and hardness of the tissue (Sharma et al, 2014). Hence, in the present study, treatment with different time of exposure was tested for sterilization of explants. In case of leaf explants, 96.39\% clean and pathogen free culture were obtained with $0.1 \%(\mathrm{w} / \mathrm{v}) \mathrm{HgCl}_{2}$ at 5 minutes showing significant traces of both bacterial as well as fungal contamination at 60
DAI. Increase in the exposure of timing to $\mathrm{HgCl}_{2}$, led to the death of explants due to the heavy metal contamination of mercury which is toxic to both plants and animal in higher concentration proving phytotoxic that is against the survival of explants. However, $\mathrm{HgCl}_{2}$ at lower concentration gives satisfactory results (Mamun et al., 2004). $\mathrm{HgCl}_{2}$ having mainly anti-bacterial property was more efficient and showed more decontamination percentage with increase in the time duration (Gochhayat et al., 2017).

Table.1 Effect of Surface sterilization time on level of contamination, aseptic culture and survival of leaf explants of Anthurium andraeanum cv. Fire at 15 DAI

\begin{tabular}{|c|c|c|c|c|c|}
\hline Treatments & Fungal \% & Bacteria \% & Blackening \% & Aseptic \% & Survival \% \\
\hline $\mathbf{T}_{1 \text { (Distilled water) }}$ & $48.28(43.92)$ & $26.80(31.18)$ & $3.79(11.23)$ & $24.92(29.94)$ & $21.13(27.37)$ \\
\hline $\mathbf{T}_{2(2 \mathrm{~min})}$ & $37.69(37.86)$ & $16.01(23.59)$ & $3.33(10.52)$ & $46.31(42.89)$ & $42.98(40.97)$ \\
\hline $\mathbf{T}_{\mathbf{3}(\mathbf{3} \text { min })}$ & $22.24(28.13)$ & $11.51(19.83)$ & $3.06(10.08)$ & $66.25(54.51)$ & $63.19(52.64)$ \\
\hline $\mathbf{T}_{4(4 \mathrm{~min})}$ & $6.45(14.48)$ & $5.13(12.96)$ & $2.72(9.49)$ & $88.42(70.38)$ & $85.71(67.79)$ \\
\hline $\mathbf{T}_{5(5 \mathrm{~min})}$ & $0.00(0.00)$ & $0.00(0.00)$ & $2.52(9.14)$ & $100.00(90.00)$ & $97.48(80.86)$ \\
\hline $\mathbf{T}_{6(6 \mathrm{~min})}$ & $0.63(4.52)$ & $0.00(0.00)$ & $3.67(11.05)$ & $99.37(85.45)$ & 95.67 (77.99) \\
\hline $\mathbf{T}_{7(7 \mathrm{~min})}$ & $0.66(4.66)$ & $0.00(0.00)$ & $5.29(13.30)$ & $99.34(85.34)$ & $94.07(75.90)$ \\
\hline $\mathbf{T}_{8(8 \text { min })}$ & $0.93(5.50)$ & $0.00(0.00)$ & $6.41(14.67)$ & $99.07(84.47)$ & $92.66(74.28)$ \\
\hline $\mathrm{CD}(0.05)$ & 1.64 & 0.48 & 0.40 & 1.88 & 1.80 \\
\hline $\operatorname{SEm}( \pm)$ & 0.55 & 0.16 & 0.13 & 0.63 & 0.60 \\
\hline
\end{tabular}

(Values in the parenthesis are Arc sign transformed values)

Table.2 Effect of Surface sterilization time on level of contamination, aseptic culture and survival of leaf explants of Anthurium andraeanum cv. Fire at 30 DAI

\begin{tabular}{|c|c|c|c|c|c|}
\hline Treatments & Fungal \% & Bacteria \% & Blackening \% & Aseptic \% & Survival \% \\
\hline $\mathbf{T}_{1}$ (Distilled water) & $50.20(45.11)$ & $31.12(33.90)$ & $4.35(12.04)$ & $18.68(25.60)$ & $14.33(22.24)$ \\
\hline $\mathbf{T}_{2(2 \min )}$ & $36.06(36.91)$ & $28.03(31.97)$ & $3.80(11.24)$ & $35.91(36.82)$ & $32.11(34.52)$ \\
\hline $\mathbf{T}_{3(3 \mathrm{~min})}$ & $20.79(27.12)$ & $17.08(27.12)$ & $3.76(11.18)$ & $62.13(52.01)$ & $58.37(49.82)$ \\
\hline $\mathbf{T}_{4(4 \mathrm{~min})}$ & $4.00(11.54)$ & 7.03(15.37) & $3.68(11.06)$ & $88.97(70.60)$ & $85.29(67.44)$ \\
\hline $\mathbf{T}_{5(5 \mathrm{~min})}$ & $0.00(0.00)$ & $0.00(0.00)$ & $3.26(10.40)$ & $100.00(90.00)$ & $96.74(79.59)$ \\
\hline$T_{6(6 \mathrm{~min})}$ & $0.96(5.46)$ & $2.38(8.87)$ & $4.75(12.59)$ & $96.66(79.47)$ & $91.91(73.47)$ \\
\hline $\mathbf{T}_{7(7 \mathrm{~min})}$ & $0.85(5.15)$ & $2.54(9.17)$ & $5.79(13.92)$ & $96.61(79.39)$ & $90.81(72.35)$ \\
\hline $\mathbf{T}_{8(8 \text { min })}$ & $1.70(7.49)$ & $2.94(9.88)$ & $6.81(17.27)$ & $95.36(77.55)$ & $88.55(70.63)$ \\
\hline $\mathrm{CD}(0.05)$ & 1.78 & 0.74 & 0.39 & 1.76 & 1.87 \\
\hline $\operatorname{SEm}( \pm)$ & 0.59 & 0.25 & 0.13 & 0.59 & 0.62 \\
\hline
\end{tabular}

(Values in the parenthesis are Arc sign transformed values) 
Table.3 Effect of Surface sterilization time on level of contamination, aseptic culture and survival of leaf explants of of Anthurium andraeanum $c v$. Fire at 45 DAI

\begin{tabular}{|c|c|c|c|c|c|}
\hline Treatments & Fungal $\%$ & Bacteria \% & Blackening \% & Aseptic \% & Survival \% \\
\hline $\mathbf{T}_{1}$ (Distilled water) & $31.54(34.16)$ & $37.82(37.95)$ & $4.77(12.62)$ & $30.65(33.62)$ & $25.88(30.58)$ \\
\hline$T_{2(2 \min )}$ & $24.98(29.99)$ & $31.93(34.41)$ & $4.27(11.92)$ & $43.09(41.02)$ & $38.82(38.54)$ \\
\hline $\mathbf{T}_{3(3 \mathrm{~min})}$ & $19.42(26.15)$ & $20.82(27.14)$ & $4.04(11.59)$ & $59.76(50.60)$ & $55.72(48.28)$ \\
\hline $\mathbf{T}_{4(4 \mathrm{~min})}$ & $5.98(14.16)$ & $7.83(16.24)$ & $3.82(12.69)$ & $86.19(68.18)$ & $82.38(65.18)$ \\
\hline $\mathbf{T}_{5(5 \mathrm{~min})}$ & $0.00(0.00)$ & $0.00(0.00)$ & $3.50(12.25)$ & $100.00(90.00)$ & $96.50(79.22)$ \\
\hline$T_{6(6 \mathrm{~min})}$ & $0.77(5.07)$ & $4.54(12.31)$ & $5.36(13.39)$ & $94.69(76.68)$ & $89.33(70.94)$ \\
\hline $\mathbf{T}_{7(7 \mathrm{~min})}$ & $0.36(3.44)$ & $4.25(11.90)$ & $5.92(14.08)$ & $95.39(77.60)$ & $89.46(71.05)$ \\
\hline $\mathbf{T}_{8(8 \text { min })}$ & $1.84(7.79)$ & $3.94(11.45)$ & $6.98(16.19)$ & $94.22(76.09)$ & $87.24(69.07)$ \\
\hline $\mathrm{CD}(0.05)$ & 1.54 & 0.56 & 0.20 & 1.68 & 1.69 \\
\hline $\operatorname{SEm}( \pm)$ & 0.51 & 0.19 & 0.07 & 0.56 & 0.56 \\
\hline
\end{tabular}

(Values in the parenthesis are Arc sign transformed values)

Table.4 Effect of Surface sterilization time on level of contamination, aseptic culture and survival of leaf explants of Anthurium andraeanum cv. Fire at 60 DAI

\begin{tabular}{|c|c|c|c|c|c|}
\hline Treatments & Fungal \% & Bacteria \% & Blackening \% & Aseptic \% & Survival \% \\
\hline $\mathbf{T}_{1}$ (Distilled water) & $10.87(19.25)$ & $41.22(39.94)$ & $5.04(12.97)$ & $47.91(43.82)$ & $42.87(40.90)$ \\
\hline $\mathbf{T}_{2(2 \mathrm{~min})}$ & $20.18(26.69)$ & $36.88(36.79)$ & $4.40(12.11)$ & $42.94(40.94)$ & $38.54(38.37)$ \\
\hline $\mathbf{T}_{3(3 \text { min })}$ & $11.87(20.15)$ & $25.24(30.15)$ & $4.27(11.92)$ & $62.90(52.48)$ & $58.63(49.96)$ \\
\hline $\mathbf{T}_{4(4 \mathrm{~min})}$ & $3.08(10.11)$ & $8.32(16.76)$ & $3.87(11.34)$ & $88.60(70.27)$ & $84.72(66.98)$ \\
\hline $\mathbf{T}_{5(5 \mathrm{~min})}$ & $0.00(0.00)$ & $0.00(0.00)$ & 3.61(10.96) & $100.00(90.00)$ & $96.39(79.04)$ \\
\hline$T_{6(6 \min )}$ & $0.55(4.27)$ & $5.64(13.74)$ & $5.48(11.54)$ & $93.81(75.60)$ & $88.33(70.03)$ \\
\hline $\mathbf{T}_{7(7 \text { min })}$ & $0.36(3.44)$ & $5.54(13.61)$ & $6.14(14.35)$ & $94.09(75.83)$ & $87.96(69.69)$ \\
\hline $\mathbf{T}_{8(8 \text { min })}$ & $1.10(6.02)$ & $5.05(12.98)$ & $7.10(15.45)$ & $93.85(75.64)$ & $86.75(68.75)$ \\
\hline $\mathrm{CD}(0.05)$ & 10.87 & 41.22 & 5.04 & 47.91 & 42.87 \\
\hline $\operatorname{SEm}( \pm)$ & 20.18 & 36.88 & 4.40 & 42.94 & 38.54 \\
\hline
\end{tabular}

(Values in the parenthesis are Arc sign transformed values)

It is concluded from the present study that broad spectrum, sterilization can assure the explants sterility and regeneration capacity which are known to be affected by exposure time to disinfectant. The leaf explants treated for 5 minutes resulted in minimum fungal $(0.00 \%)$ and bacterial $(0.00 \%)$ contamination with maximum survival percentage $(100 \%)$.These findings will facilitate a good base for competent and effortless surface sterilization of Anthurium andraeanum $c v$. Fire leaf explants especially when they are collected from field condition. Present study also revealed that surface sterilization of
Anthurium andraeanum $c v$. Fire leaf explants can be used to produce callus in vitro which could further be used to produce healthy plantlets under the aseptic condition on large a number and a less time.

\section{References}

CBI Market Intelligence, 2016. Trade Statistics Cut Flowers and Foliage, 2.

Gochhayat, A. A., Beura, S., and Subudhi, E., (2017). Effect of Surface Sterilization Time and Plant Bioregulators for Callus Formation in Hybrid Lilium 
Cv. Tresor. Biosciences biotechnology research asia, 14(2): 709-713.

Gomez, K. A., and Gomez, A. A., (1984). Statistical procedures for agricultural research 3rd edn, John Wiley and Sons, Singapore., 680.

Leifert, C., Waites, W. M., and Nicholas, J. R., (1989). Bacterial contaminants of micropropagated plant cultures. J. App. Bacterol. 67:353-361.

Leifert, C., Morris, E. C., and Waites, W. M., (1994). Ecology of microbial saprophytes and pathogens in field grown and tissue cultured plants. Cri. Reviews Plant Sci. 13:139-183.

Mamun, M. A., Sikdar, M. B. H., Paul, D. K., Rahman, M. M., and Islam, M. R., (2004). In vitro micropropagation of some important sugarcane varieties of
Bangladesh. Asian J. Plant Sci., 3: 666-669.

Murashige, T., and Skoog, F., (1962). A revised medium for rapid growth and bioassays with tobacco cultures. Physiologia Plantarum., 15(3): 473497.

Rezadost, H. M., Sohan, M. M., and Hatamzadeh, A. M. R. M., (2013). In vitro regeneration of sour orange (Citrus aurantium L.) via direct organogenesis: Plant Knowledge Journal; 2: 150-156.

Sharma, V., Srivasta N., Kamal B., Dobriyal, A.K., and Jadon S.V., (2014). Efficient sterilization protocols for different explants of an endangered: Trends in life sciences, www.sciencejournal.in, 3: 2319-5037.

\section{How to cite this article:}

Rashmita Toppo and Sashikala Beura. 2018. Effect of Surface Sterilization Time on leaf Explants for Aseptic Culture in Anthurium adraeanum (Hort.) $c v$. Fire Int.J.Curr.Microbiol.App.Sci. 7(07): 2509-2515. doi: https://doi.org/10.20546/ijcmas.2018.707.294 